\section{Consultant manpower (2)}

Sir: Dr Jarrett is to be congratulated on drawing attention to the serious consultant manpower shortage in psychiatry (Psychiatric Bulletin. September 1995, 19, 573-576). One only has to look at the British Medical Journal to realise from the numbers and increasing size of advertisements for consultant psychiatrists that the situation is becoming desperate. A long-term consultant vacancy in a psychiatric unit puts considerable stress on the other consultants and on the trainees, leading to deterioration in patient care and psychiatric training. The remaining consultants are then tempted to move to more attractive units so that large areas would be left with only a rudimentary psychiatric service.

Unfortunately Dr Jarrett's suggestions for improving the situation are of limited value. Apart from moral questions involved in trying to retain overseas doctors in this country, the changes in the Home Office regulations would take too long to implement. The suggestion of helping psychiatrists caught in the locum consultant 'trap' is worthwhile on humanitarian grounds, but is unlikely to make much impact on the manpower problem.

There is, however, one measure which if adopted by the College would produce an immediate improvement. The current College requirement that senior registrars must spend three years in the grade before applying for consultant posts is arbitrary and relatively recent. As there are approximately 600 senior registrar posts in England and Wales, if the minimum time in the grade was reduced to two years, then immediately up to 200 senior registrars would become eligible to apply for consultant posts. This would also temporarily ease or remove the senior registrar 'bottle-neck'. One can understand the reluctance of our College to take this step, but I suggest that our profession is facing a psychiatric emergency.

ERIC BIRCHALL

Fazakerley Hospital, Liverpool L9 7AL

Sir: Using adult mental illness as an example, the published figures provide some support for $\mathrm{Dr}$ Birchall's proposals. On 30 September 1993 there were 437 senior registrars in post and 251 consultant vacancies advertised in the year following (Wilson \& Allen, 1994). If senior registrar training were two years long then 220 consultants would become available a year - still leaving a 30 post shortfall, but a definite improvement on the 142 or 105 shortfall with a three or four year senior registrar training respectively.

Whether 220 consultant posts could be filled annually for the indefinite future is uncertain while we are so ignorant of the reasons for the consultant shortfall. What the implications are of such a plan for the quality of consultant postholders is another question.

In our state of ignorance about the consultant shortfall it is particularly unfortunate that we have now lost the information most generally avallable for understanding it. For some years now, Health Trends have published an annual article on medical manpower. I recently learnt from the Department of Health's Health Care Directorate (medical education, training and staffing) that this series has been discontinued and furthermore, that the tables on which the articles were based are no longer to be prepared. Given the increasing importance that medical manpower shortages are assuming, it is hard not to be cynical about the change.

This change, though, makes it even more important for the College to improve its data about medical manpower and posts. I should like to suggest that, to increase precision in the College's annual data collection, each established consultant post be assigned a number. If each post holder also had a number (the General Medical Council number could be used), the annual returns could provide a picture of trends in manpower movement which could be invaluable in planning. Indeed, by incorporating the shortly to be introduced trainee ID numbers and numbering established junior posts as well, a very full picture of the manpower situation could emerge.

WILSON, R. \& ALLEN, P. (1994) Medical and dental staffing prospects in the NHS in England and Wales, 1993. Health Trends, 26, 70-79.

PETER JARRETT

Greenwich Mental Health and

Learning Disability Services, Psychiatric Department, David Leiberman Centre, Greenwich SE1O

\section{Life, death and compassion}

Sir: I was surprised and delighted once more to hear the voice of Stafford-Clark (Psychiatric Bulletin, August 1995, 19, 504-505). Although it is now 48 years ago (he a registrar, I a lowly house officer) at the Maudsley Hospital weekly conferences presided over by the awesome Aubrey Lewis - I still vividly remember StaffordClark's lively, cheerful presentations, his breadth of vision, refusal to be intimidated or confined by any orthodoxy.

Stafford-Clark reminds us that we have not only a duty to be honest, lucid and compassionate when dealing with patients and their relatives confronting fatal illnesses, but that we must also "be informed by a dedicated and dispassionate kind of love", as well as listening 
to our patients in such a way that they are fully understood.

What I wish to add is that the doctor, if he is to show the sensitivity needed under the circumstances, must himself have confronted, and worked through in his imagination, the despair, fear, and grief, of his own future death - and as a result to have achieved equanimity in the face of this universal reality.

U. B. H. BARUCH

2 Queen's Walk, Ealing, London W5 1TP

\section{The integration of psychiatry and peychotherapy}

Sir: We were delighted to read Jeremy Holmes optimistic editorial (Psychiatric Bulletin, August 1995, 19, 465-466) regarding the integration of the specialities of psychiatry and psychotherapy. However, a major omission was the thorny issue of training. Why does an organisation like the NHS specify the need for psychoanalytic and other psychotherapies, yet not accept any responsibility for comprehensive training?

It is specifically to avoid delivering care in a 'vaguely psychodynamic' and possibly harmful way that many junior doctors seek a systematic training in psychoanalytic individual, group, or family psychotherapy at their own expense. The Royal College of Psychiatrists (Grant et al, 1993) states that experience in individual dynamic psychotherapy is a mandatory requirement for qualification, and acknowledges the "danger of the devaluation of the need for rigorous training". A recognition of the sparse supervision available within the NHS, and work demanding a high level of therapeutic skill, fuel the wish to be properly trained, even if one does have to fund it oneself and accommodate the training around ones' fulltime NHS job. Private training organisations' fees and training analyses can cost up to $£ 15-30000$ over several years. Many would deem anyone taking on such training at personal cost as misguided; yet we believe that many trainees see themselves as having little choice. Additionally. doctors are disadvantaged compared to nonmedical colleagues in attempting to recoup their training expenditure by practising privately, not being allowed to advertise or have a listing on registers which are available to the public (British Medical Association, 1991).

It has been said that in the United States "psychotherapy is rapidly becoming an endangered species" (Wallerstein, 1991) due to a reduction in core junior doctor psychotherapeutic training. Here in the UK, the reality of limited funding must encourage the split that Holmes describes. This split strengthens the identity of each discipline at the expense of mutually beneficial working arrangements. Joint training arrangements could serve as a focus of increasing cooperation, yet there is little comment on how to facilitate comprehenstve training within the NHS and for the benefit of NHS patients.

BRTTSH MEDICAL ASSOCIATON (1991) Guidelines to Doctors on Advertising. London: BMA.

GRANT, S., HoLmES, J. \& WATSON, J. (1993) Guidelines for psychotherapy training as part of general professional psychiatric training. Psychiatric Bulletin, 17, 695-698.

WALLERSTEIN. R. S. (1991) The future of psychotherapy. Bulletin of the Menninger Clinic, 65, 421-443.

K. BHUl and A. AUBIN

The Maudsley Hospital, London SE5 8AZ

Sir: Dr Jeremy Holmes has cited me inaccurately (Psychiatric Bulletin. August 1995, 19, 465) in writing that "Marks now concedes that psychoanalytic psychotherapy has a role in the longterm treatment of patients with personality disorder".

The passage referred to (British Medical Journal, 309, 1072) in fact read: "It would be justifiable to give some patients with chronic personality problems prolonged psychotherapy in the NHS if benefit from it is shown and there are no good brief alternatives. Unless value is proved, however, prolonged treatment should not be part of routine care." A different meaning somehow.

ISAAC MARKS

Professor of Experimental Psychopathology. Institute of Psychiatry.

De Crespigny Park, London SE5 8AF

\section{Reducing non-attendence at out-patient clinics}

Sir: Rusius (Psychiatric Bulletin, May 1995, 19. 291-292) rightly emphasises the costly nature of non-attendance at out-patient clinics. An alternative method of reducing non-attendance is to visit the patient at home.

For a four year period (1989-1992) one of us (DA) prospectively studied a domiciliary clinic in an old age psychiatric service. All new out-patient referrals were seen in their own home for initial assessment. Non-attendance rates were compared with a traditional hospital clinic run by the second consultant in the department. Nonattendance rate for the domiciliary clinic was $1.7 \%$ (8 of 462 referrals) and the hospital clinic $21.2 \%$ (57 of 269 referrals). Non-attendance for 